\title{
Diagnostic value of neurotrophin expression in malignant pleural effusions
}

\author{
BERNARD C. DUYSINX, ASTRID PAULUS, VINCENT HEINEN, DELPHINE NGUYEN, \\ MONIQUE HENKET, JEAN-LOUIS CORHAY and RENAUD LOUIS
}

\begin{abstract}
Division of Pulmonary Medicine and GIGA Infection, Immunity and Inflammation Research Group, University of Liège, CHU Sart-Tilman, Liège 4000, Belgium
\end{abstract}

Received January 21, 2011; Accepted May 31, 2011

DOI: $10.3892 /$ etm.2011.302

\begin{abstract}
Neurotrophins (NTs) modulate the growth of human malignancies, including lung cancers. Our prospective study evaluated the accuracy of pleural NTs [nerve growth factor, brain-derived neurotrophic factor (BDNF), neurotrophin 3 (nT3) and 4 (nT4)] levels for differentiating benign from malignant pleural exudates. Levels of NTs were measured by ELISA in 170 patients with non-neutrophilic $(<50 \%)$ exudative benign or malignant pleurisies diagnosed by pleuroscopy. Fifty-nine benign (9 infections and 50 inflammatory diseases) and 111 malignant (50 extrathoracic tumors, 51 lung cancers and 10 mesotheliomas) pleural exudates were diagnosed by thoracoscopy. Levels of BDNF were significantly higher in malignant than in benign effusions $[17 \mathrm{pg} / \mathrm{ml}(0-367) \mathrm{vs} .8 \mathrm{pg} / \mathrm{ml}(0-51)$, $\mathrm{p}<0.05]$. ROC analysis showed an area under the curve of 0.609 ( $\mathrm{p}=0.012$; best threshold $44 \mathrm{pg} / \mathrm{ml})$. Pleural BDNF levels were significantly higher in pleural metastasis of pulmonary tumors and in mesothelioma than in pleural benign effusions. Finally, a higher proportion of pleural nT3 was detected in squamous cell lung carcinoma in comparison to that in nonsquamous cell lung carcinoma (72.7 vs. $10 \%, \mathrm{p}<0.0001)$. NTs and particularly BDNF may play a role in the pathogenesis of malignant pleural effusions.
\end{abstract}

\section{Introduction}

Pleural effusion is a common problem which manifests in a wide range of local and systemic potentially life-threatening diseases. Accurate diagnosis is difficult without resorting to invasive procedures. In particular, diagnosis of malignant pleural effusion presents a challenge since its differentiation from benign effusion is often difficult using currently available parameters derived from thoracosynthesis. Although essential for distinguishing between a transudate and exudate

Correspondence to: Dr Bernard Duysinx, Division of Pulmonary Medicine, CHU Sart Tilman B35, B-4000 Liège, Belgium

E-mail: bduysinx@swing.be

Key words: neurotrophin, pleural effusion, cancer, lymphocyte effusion, exudate
(1), biochemical, microbiological and cytological pleural fluid analyses have poor value for identifying the cause of a pleural lymphocytic exudate (2). The sensitivity of cytological examination of pleural fluid and blind needle biopsy, even when combined together, is generally less than $75 \%(3-7)$. Although there is a huge interest in biomarkers (cytokines, matrix metalloproteinases, growth factors and tumor markers) for the diagnosis of pleural effusions, their lack of sensitivity and specificity limits their use. Moreover, there is a lack of accepted and reliable diagnostic criteria particularly for malignancy based on morphological imaging (CT and MR imaging) (8-10). The development of inflammation in the pleura results in an increased vascular permeability, and pleural liquid accumulation is the result of increased fluid production and/ or reduced lymph drainage. This pleural fluid is enriched in proteins, inflammatory cells and mediators $(5,11)$. Cytokineproducing cells and cytokines, such as the vascular endothelial growth factor (VEGF) which is able to increase angiogenesis and enhance the permeability of vascular endothelial cells $(12,13)$, are thought to be important in malignant pleural fluid formation $(14,15)$.

In malignant pleural effusion, neoplastic cells infiltrate the pleural layer and growth progressively in the pleural cavity.

Nerve growth factor (NGF), brain-derived neurotrophic factor (BDNF), neurotrophin 3 (nT3) and neurotrophin 4 (nT4) comprise the mammalian neurotrophins (NTs), a family of structurally related growth factors that play a crucial role in the survival, development, differentiation, neurite outgrowth and maintenance of a specific neuronal population in the nervous system $(16,17)$. They belong to a class of growth factors, secreted proteins, which are capable of signaling particular cells to survive, differentiate or grow mediated by two classes of receptors, p75 and the 'Trk' family of tyrosine kinase receptors.

Although classically known for their effects on neurons, NTs are multifunctional growth factors and exert numerous effects including differentiation of B-lymphocytes (18), histamine release from mast cells (19), formation of intramyocardial blood vessels (20) and growth of follicles in the ovaries (21) on non-neuronal cells, particularly in immunocompetent cells and lymphoid organs (22). Interest in the NTs system has grown particularly in regards to several lung diseases (23-26). Under normal conditions, Trk B (the physiological high-affinity 
receptor for BDNF) has been found to be involved in the development and maintenance of the normal structure of the lung $(27,28)$. In addition, NTs play a role in the modulation of certain human malignancies $(29,30)$, such as myeloma (31), fibrosarcoma (32), hepatocellular (33) and pancreatic (34) carcinoma as well as lung cancer $(35,36)$. More importantly, there is in vitro evidence that compounds blocking NT signaling, such as k252a, are able to block lung cancer cell progression (37). Yet, to date, the role of NTs in malignant pleural effusion (38) and in mesothelioma (39) has been poorly investigated.

In the present study, we aimed to ascertain whether determination of levels of four NTs (NGF, BDNF, nT3 and nT4) in pleural fluid aids in identifying the etiology of non-neutrophilic pleural effusions and, in particular, in differentiating malignant from benign effusions.

\section{Materials and methods}

Patient selection. We conducted a prospective study, including 170 consecutive patients (mean age 66.4 13.4 years; range 18-96; 98 males and 72 females) who were treated at the Pneumology Department, CHU, Liège, between 2004 and 2009. All patients presented with an exudative pleural effusion for whom the combination of chest X-ray, thoracic CT scanning (PQ 2000 4th generation; Picker, Cleveland, $\mathrm{OH}, \mathrm{USA}$ ) and thoracocentesis failed to provide an etiologic diagnosis. Therefore, the indication for thoracoscopy was justified along with pleural biopsy. In the chemical analysis, pleural effusion was considered to be an exudate according to Light's criteria (1). Thus, the pleural effusion had to meet at least one of the following criteria: ratio of pleural fluid protein to serum protein $>0.5$; ratio of pleural fluid lactic dehydrogenase $(\mathrm{LDH})$ to serum lactic dehydrogenase $>0.6$; pleural fluid lactic dehydrogenase level greater than two-thirds of the upper limit of the serum normal value. Neutrophilic pleurisy $(>50 \%$ neutrophils) (2) and empyema were excluded from this study. In our series thoracoscopy procedure allowed establishment of a diagnosis in each case.

Pleural fluid analysis. A diagnostic thoracocentesis of the pleural fluid $(10 \mathrm{ml})$ was performed on each subject before thoracoscopy was carried out. A first sample of $5 \mathrm{ml}$ was subjected to routine biochemical analysis, including tests for pleural protein, glucose, $\mathrm{LDH}$ and amylase levels. A second sample of $5 \mathrm{ml}$ was added to a tube containing ethylenediamino-tetraic-potassium anticoagulant for differential cell counting.

For NTs measurements, $20 \mathrm{ml}$ of pleural fluid was centrifuged at $400 \mathrm{x} \mathrm{g}$ for $10 \mathrm{~min}$ at $4^{\circ} \mathrm{C}$. The supernatant was separated from the cell pellet. The supernatant was immediately stored at $-70^{\circ} \mathrm{C}$ until the ELISA was performed.

NTs (BDNF, NGF, nT3 and nT4) levels were determined according to the following commercially available enzymelinked immunosorbent assay (ELISA) kit (Duoset; R\&D Systems Europe, Abingdon, UK). The ELISA was validated by determination of the assay sensitivity and spiking recovery. Assay sensitivity was determined by calculating the mean response of 10 sets of blanks and evaluating the mean plus 2 standard deviations on the standard curve. The limit of detection was $5 \mathrm{pg} / \mathrm{ml}$ for BDNF, NGF and nT3 and $10 \mathrm{pg} / \mathrm{ml}$ for nT4. Spiking recovery was determined by adding $0,7.5,15.6$,
Table I. Demographic characteristics and etiologies of the patients with malignant or benign pleural effusions.

Benign pleural effusions

Age (years) $\quad 68 \pm 13$
Gender $(\mathrm{M} / \mathrm{F})$
Etiology
Infectious pleurisies $(\mathrm{n}=9)$
6 parapneumonic pleurisies
3 tuberculosis
Inflammatory pleurisies $(\mathrm{n}=50)$
1 Dressler's syndrome
2 chronic pancreatitis
3 heart failures
1 post-radic
6 benign asbestos
1 uremic
1 drug-induced
1 post-traumatic
3 connective tissue diseases
2 rheumatoid arthritis
1 scleroderma
40 non-specific chronic inflammatory changes

Malignant pleural effusions

Age (years) $65 \pm 14$
Gender $(\mathrm{M} / \mathrm{F})$
Etiology
Pleural metastases of extrathoracic tumors $(\mathrm{n}=50)$
18 breast cancers
5 ovarian cancers
5 kidney cancers
7 pancreatic cancers
4 colic tumors
2 rectal carcinomas
2 prostatic carcinomas
2 lymphomas
1 skin cancer
1 genital carcinoma
1 acute leukemia
1 laryngeal cancer
1 unknown primary
Pleural metastases of lung cancer (n=51)
11 squamous non-small-cell carcinomas
31 adenocarcinomas
5 large-cell carcinomas
2 sarcomas
2 small-cell lung cancers
Mesothelioma (n=10)

$31.2,62.5,125,250$ and $500 \mathrm{pg} / \mathrm{ml}$ of NTs to a pool of 10 pleural liquids. The recovery for BDNF, NGF, nT3 and nT4, at a concentration of $62.5 \mathrm{pg} / \mathrm{ml}$, was $99,61,>96$ and $80 \%$, respectively. 
Table II. Pleural cell counts and biochemical parameters in the malignant and benign pleural effusions.

\begin{tabular}{lcc}
\hline & Benign pleural effusions $(\mathrm{n}=59)$ & Malignant pleural effusions $(\mathrm{n}=111)$ \\
\hline $\mathrm{RBC} / \mathrm{mm}^{3}$ & $2,515(40-720,000)$ & $4,640(0-1,840,000)$ \\
$\mathrm{WBC} / \mathrm{mm}^{3}$ & $710(85-14,920)$ & $600(4-10,000)$ \\
Neutrophils $(\%)$ & $6(0-47)$ & $11(0-49)$ \\
Lymphocytes $(\%)$ & $62(3-98)$ & $52(0-100)$ \\
Reticulo/monocytes $(\%)$ & $15(0-83)$ & $22(0-94)$ \\
Eosinophils $(\%)$ & $2(0-73)$ & $1(0-43)$ \\
Proteins $(\mathrm{g} / \mathrm{l})$ & $42(20-62.9)$ & $41.3(10-68.3)$ \\
LDH (UI/l) & $420(286-1,735)$ & $551(120-6,512)$ \\
Amylase (UI/l) & $39(12-22,540)$ & $37.5(4-903)$ \\
Glucose (g/l) & $0.90(0.02-1.94)$ & $0.84(0.14-2.73)$ \\
Protein Pl/blood ratio & $0.60(0.28-0.88)$ & $0.62(0-1.16)$ \\
LDH Pl/blood ratio & $0.94(0.15-33)$ & $1.40(0-27)^{\mathrm{a}}$ \\
\hline
\end{tabular}

Values are expressed as median (range); ${ }^{\mathrm{a}} \mathrm{p}<0.05$.

Etiologic diagnosis of pleural exudate. The final diagnosis of the pleural effusion was obtained by invasive pleural biopsy during a thoracoscopy. When a diagnosis of benign disease was established, based on histopathology, the patients were followed up for at least 18 months to ensure absence of a malignant pleural process. Benign pleural effusions included both infectious (parapneumonic and tuberculosis) and inflammatory pleural effusions. Malignant pleural effusions were divided into three groups: i) pleural metastasis of an extrathoracic cancer, ii) pleural metastasis of a primary lung cancer and iii) mesothelioma.

The size of the pleural effusion was estimated in each patient by the total pleural fluid volume aspirated when starting the thoracoscopy procedure.

The protocol was approved by the local ethics committee, and informed consent was obtained from each subject prior to the study.

Statistical analysis. All data were expressed as the median (range) levels for pleural cell counts, pleural biochemical parameters and NTs. Characteristics of pleural fluid and pleural cell counts in malignant vs. benign pleural effusion were compared using the non-parametric Mann-Whitney test. A KruskallWallis analysis (Dunn's multiple comparisons post-test) was used to compare pleural neurotrophin levels in subgroups of malignant vs. benign pleural effusions. To calculate correlations between variables, the Spearman rank coefficient of correlation was used. The accuracy of each pleural NT to distinguish malignant from benign pleural lesions was calculated with receiver operating characteristic (ROC) analyses. A p-value $<0.05$ was considered statistically significant.

\section{Results}

Clinical diagnosis. Thoracoscopic biopsies indicated benign pleural lesions in 59 patients and malignant pleural effusions in 111. Demographic characteristics and pleural effusion etiologies are provided in Table I. The gender ratio was different with females accounting for $45 \%$ of the malignant group, while only representing $36 \%$ of the benign group (NS).

Pleural cell counts and biochemical parameters. Biochemical and cytological characteristics of the pleural effusions are provided in Table II. There was no significant difference in pleural protein, LDH, glucose and amylase level and in protein Light's ratio between the malignant and benign pleural effusions. However, LDH Light's ratio was significantly higher in the malignant effusions $(\mathrm{p}<0.05)$ (Table II). There was no significant difference in pleural cell counts between the benign and malignant effusions (Table II).

None of the pleural samples showed a positive bacterial growth during the culture, even when the pleural effusion was deemed to be of infectious origin.

Determination of neurotrophins in pleural effusions. The median level of pleural BDNF was $17 \mathrm{pg} / \mathrm{ml}(0-367)$ in patients with malignant pleural effusions, which was significantly higher compared to the value of $8 \mathrm{pg} / \mathrm{ml}(0-51)$ found in benign effusions $(\mathrm{p}<0.05)$ (Table III). By contrast, no significant difference was found in NGF and nT3 pleural levels between malignant and benign effusions (Table III). nT3 was only observed in $13.5 \%$ of the 170 pleural effusions, including 8 and $16 \%$ of benign and malignant effusions, respectively (NS). nT4 was undetectable with the exception of 1 patient with pleural metastasis of squamous lung carcinoma.

Pleural BDNF levels were positively correlated with pleural red cell counts $(r=0.29, p<0.001)$, pleural neutrophil counts $(\mathrm{r}=0.16, \mathrm{p}<0.05)$ and with pleural effusion volume $(\mathrm{r}=0.19$, $\mathrm{p}<0.05)$. BDNF was negatively correlated with pleural eosinophil counts $(r=-0.22, p<0.05)$ and pleural glucose $(r=-0.22$, $\mathrm{p}<0.01)$. No correlation was found with total pleural protein levels $(\mathrm{r}=-0.10, \mathrm{p}>0.05)$.

ROC curve of BDNF for distinguishing between malignant and benign effusions is presented in Fig. 1. Only the measurement of BDNF showed significant value in identifying malignant effusions with an area under the curve (AUC) of 
Table III. Comparison of pleural neurotrophin levels in benign and malignant pleural effusions.

\begin{tabular}{llc}
\hline $\begin{array}{l}\text { Pleural } \\
\text { neurotrophins }\end{array}$ & $\begin{array}{c}\text { Benign pleurisy } \\
(\mathrm{n}=59)\end{array}$ & $\begin{array}{c}\text { Malignant pleurisy } \\
(\mathrm{n}=111)\end{array}$ \\
\hline BDNF $(\mathrm{pg} / \mathrm{ml})$ & $8(0-51)$ & $17(0-367)^{\mathrm{a}}$ \\
NGF $(\mathrm{pg} / \mathrm{ml})$ & $0(0-120.3)$ & $0(0-376)$ \\
$\mathrm{nT} 3(\mathrm{pg} / \mathrm{ml})$ & $0(0-43)$ & $0(0-137)$ \\
$\mathrm{nT} 4(\mathrm{pg} / \mathrm{ml})$ & $0(0-0)$ & $0(0-28)$ \\
\hline
\end{tabular}

Values are expressed as median (range); ${ }^{\mathrm{a}} \mathrm{p}<0.05$.

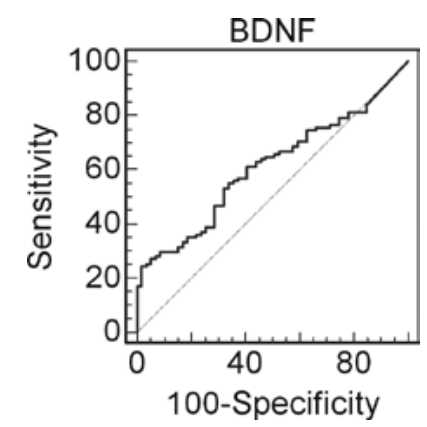

Figure 1. Receiving operating characteristic (ROC) curves of BDNF for differential diagnosis (malignant vs. benign) of the pleural effusions.

$0.609(\mathrm{p}<0.05)$. Derived from this curve, the best cut-off point was found to be $44 \mathrm{pg} / \mathrm{ml}$ which gave a sensitivity, a specificity and an accuracy of 24, 99 and 50\%, respectively. Sensitivities and specificities for different cut-off values for distinguishing benign from malignant pleurisies are presented in Table IV.

Regarding different subgroups of malignant and benign pleural effusions, a significant difference in pleural BDNF levels was noted, which was significantly higher in pleural metastasis of lung cancer and in mesothelioma when compared to benign effusions [19 $\mathrm{pg} / \mathrm{ml}(0-232)$ and $27 \mathrm{pg} / \mathrm{ml}(0-367)$ vs. $8 \mathrm{pg} / \mathrm{ml}(0-51)$, respectively, p<0.05] (Fig. 2). ROC analysis showed BDNF may help to distinguish between pleural metastasis of lung cancer and benign effusion $(\mathrm{AUC}=0.664, \mathrm{p}<0.01$; 72 and $59 \%$ for sensitivity and specificity, respectively, for best threshold of $11 \mathrm{pg} / \mathrm{ml}$ ), and between pleural metastasis of lung and extrathoracic cancers (AUC $=0.613, \mathrm{p}<0.05 ; 69$ and $56 \%$ for sensitivity and specificity, respectively, for best threshold of $12 \mathrm{pg} / \mathrm{ml}$ ) (Table V). Finally, there was a strong trend for BDNF to identifying mesothelioma from benign effusion (AUC $=0.703, \mathrm{p}=0.055 ; 40$ and $100 \%$ for sensitivity and specificity, respectively, for best threshold of $51 \mathrm{pg} / \mathrm{ml}$ ). We found no significant difference in the four neurotrophin levels according to the etiology of the benign pleural effusions [infectious $(n=9)$ vs. inflammatory $(n=50)]$.

In malignant pleural effusions, pleural nT3 concentrations were observed in $10 \%$ of pleural metastasis of extrathoracic cancer, in $10 \%$ of mesothelioma and in $23.5 \%$ of pleural metastasis of primary lung cancer (NS). In this last subgroup, a higher proportion of pleural nT3 was detected in squamous cell carcinoma in comparison to that in non-squamous cell carcinoma (72.7 vs. $10 \%$, p<0.0001) (Fig. 3).
Table IV. Sensitivities, specificities, negative predictive value (NPV) and positive predictive value (PPV) for different cut-off values derived from ROC curves of BDNF for distinguishing benign from malignant pleurisies.

\begin{tabular}{lcccc}
\hline $\begin{array}{c}\text { Cut-off } \\
(\mathrm{pg} / \mathrm{ml})\end{array}$ & $\begin{array}{c}\text { Sensitivity } \\
(\%)\end{array}$ & $\begin{array}{c}\text { Specificity } \\
(\%)\end{array}$ & $\begin{array}{c}\text { NPV } \\
(\%)\end{array}$ & $\begin{array}{c}\text { PPV } \\
(\%)\end{array}$ \\
\hline 10 & 63 & 54 & 44 & 72 \\
15 & 53 & 68 & 43 & 76 \\
20 & 47 & 71 & 39 & 73 \\
25 & 39 & 71 & 39 & 73 \\
30 & 39 & 75 & 39 & 73 \\
35 & 33 & 81 & 39 & 77 \\
40 & 28 & 91 & 41 & 86 \\
45 & 24 & 98 & 41 & 96 \\
50 & 17 & 98 & 39 & 95 \\
\hline
\end{tabular}

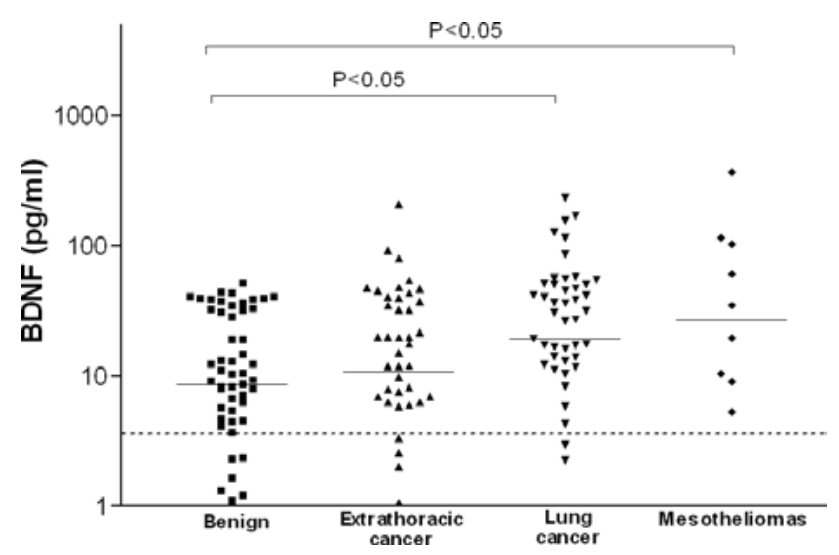

Figure 2. Comparison of pleural BDNF levels in different subgroups of pleurisy (benign effusion, pleural metastasis of extrathoracic tumor, pleural metastasis of lung cancer and mesothelioma). Dashed line represents the limit of the detection of our assay. Solid line represents the median value in the different pleurisies.

\section{Discussion}

The aim of the present study was to assess the levels of NTs in pleural effusion where etiology was not obvious. The present study demonstrated for the first time in a large and wellcharacterized population of patients with non-neutrophilic exudates that, even though the pleural BDNF level was higher in malignant pleural effusions, it exhibited a rather limited clinical value in distinguishing between malignant and benign pleural effusions.

ROC curve analysis indicated that BDNF at a concentration of $44 \mathrm{pg} / \mathrm{ml}$ yields the best compromise between sensitivity and specificity, although we recognize it to be fairly modest as a diagnostic tool due to a low sensitivity (24\%). However, this can be compared to what is usually found with chest CT scanner which has a sensitivity that may range from 22 to $35 \%$ according to the morphological chosen criteria (40), while specificity is around $80 \%$.

Even though several NTs were reported to influence extrathoracic neoplastic cell differentiation and growth (29-32,41), in our study only BDNF levels were found to be significantly 
Table V. Receiving operating characteristics (ROC) curves of BDNF for distinguishing between the subgroups of pleural effusions.

\begin{tabular}{lccccc}
\hline & AUC & p-value & Cut-off (pg/ml) & Sensitivity & Specificity \\
\hline $\begin{array}{l}\text { Lung cancer pleural metastasis } \\
\text { vs. benign pleurisy }\end{array}$ & 0.664 & 0.002 & 11 & 72 & 59 \\
$\begin{array}{l}\text { Lung cancer vs. extrathoracic } \\
\text { tumor pleural metastasis }\end{array}$ & 0.613 & 0.040 & 12 & 69 & 56 \\
$\begin{array}{l}\text { Lung cancer pleural metastasis } \\
\text { vs. mesothelioma }\end{array}$ & 0.516 & 0.590 & 57 & 40 & 88 \\
$\begin{array}{l}\text { Extrathoracic tumor pleural } \\
\text { metastasis vs. benign pleurisy }\end{array}$ & 0.534 & 0.550 & 43 & 55 & 97 \\
$\begin{array}{l}\text { Extrathoracic tumor pleural } \\
\text { metastasis vs. mesothelioma }\end{array}$ & 0.661 & 0.130 & 50 & 40 & 94 \\
\begin{tabular}{l} 
Mesothelioma vs. benign pleurisy \\
\hline
\end{tabular} & 0.703 & 0.055 & 51 & 100 \\
\hline
\end{tabular}

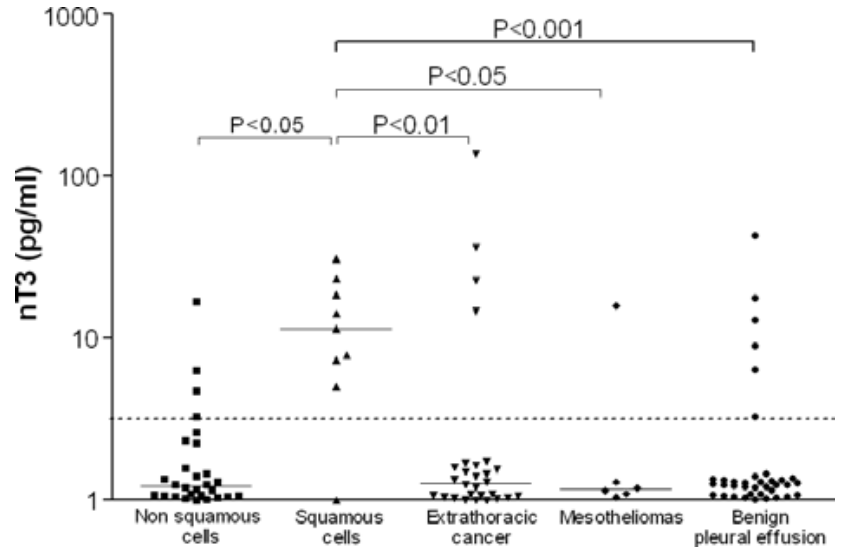

Figure 3. Comparison of pleural nT3 levels according to pleural metastasis of primary lung tumor histology (squamous cell carcinoma vs. non-squamous), pleural metastasis of extrathoracic tumor, mesothelioma and benign pleural effusions. Dashed line represents the limit of the detection of our assay. Solid line represents the median value in the different pleurisies.

increased in malignant effusions. Moreover, these increased levels were essentially due to lung cancer pleural metastasis and mesothelioma.

Our study confirms in a larger series of patients the results of Ricci et al who reported significantly higher concentrations of BDNF in malignant pleural effusions in comparison to inflammatory exudates and transudates (38).

The reason why BDNF is increased in malignant effusions is not clear. Although we cannot exclude that increased BDNF levels may partly be related to increased pleural endothelial permeability, the lack of correlation between pleural BDNF and protein levels suggests that there may be additional mechanisms involved. Local production of BDNF by mesothelial cells, recruited inflammatory and malignant cells is likely to contribute to the increased levels found in malignant effusions and points to the existence of an autocrine and/ or paracrine mechanism $(35,36,38)$. Although we excluded pleural fluids with high neutrophil counts $(>50 \%)$, we found a significant correlation between neutrophil counts and BDNF suggesting that recruited neutrophils may contribute together with tumoral cells to local BDNF production.
In contrast, the absence of a correlation between pleural $\mathrm{LDH}$, a marker of tumor activity, and BDNF supports the hypothesis that pleural BDNF levels may not be directly related to tumor growth itself, but rather to an interaction between malignant cells and local mesenchymal or inflammatory cells. The significant relationship between the volume of pleural effusion and BDNF is in keeping with the role of this NT in controlling pleural fluid homeostasis $(35,38)$. Implication of BDNF in vascular permeability regulation is further supported by the recognition of its involvement in cerebral edema and subsequent neuronal tissue damage (42).

Immunohistochemical analysis showed that Trk B receptors, the BDNF receptors, were expressed in several neoplastic cells, fibroblasts and blood vessels $(21,35)$. Activation of Trk B receptors may be a key mechanism in tumor cell survival after detachment from extracellular matrix (a process called 'anoikis') (43). The particularly elevated levels of BDNF in malignant pleural fluid from lung cancer cells known to express high level of Trk B receptors (36) may cause a more aggressive pleural invasion as compared to extrathoracic tumors. Notably, an inverse relationship was found between pleural glucose and BDNF levels. This supports the idea that BDNF is increased when metabolic activity of the pleura is intense as in tumor cell proliferation $(44,45)$. Additionally, a strong correlation was found between pleural red cell counts and BDNF levels which is in line with the role of BDNF in pleural neoangiogenesis, a phenomenon critical for tumor proliferation.

In contrast to BDNF, neither NGF nor nT3 were found to be significantly increased in pleural effusion of malignancies. Furthermore, nT3 pleural levels were only detected in $13.5 \%$ of all pleurisies, with a trend to a higher percentage of detection in malignant pleurisies $(16 \%)$ vs. benign effusion $(8 \%)$. Pleural nT3 level was observed in the majority of squamous cell lung carcinoma (73\% of cases) which sharply contrasts to what was observed in other types of lung cancer histology $(\sim 10 \%)$. Our data corroborate those reported by Ricci et al for lung surgical samples (36).

NGF has been reported to be more commonly a regulator of differentiation and/or survival than a cancer cell growth factor (38). Down-regulation of NGF has even been demonstrated in aggressive human malignancies (46). In light of this view, we 
find no surprise that NGF levels were not increased in the malignant pleural effusions.

In conclusion, albeit of a limited diagnosis value, our results demonstrated in a large patient series that malignant pleural effusions display increased BDNF levels which may contribute to the local growth and invasiveness of tumors. This may offer a novel target in the treatment strategy for malignant pleural diseases.

\section{References}

1. Light RW, Macgregor MI, Luchsinger PC and Ball WC Jr: Pleura effusions: the diagnostic separation of transudates and exudates. Ann Intern Med 77: 507-513, 1972.

2. Light RW, Erozan YS and Ball WC Jr: Cells in pleural fluid. their value in differential diagnosis. Arch Intern Med 132: 854-860, 1973

3. Poe RH, Israel RH, Utell MJ, Hall WJ, Greenblatt DW and Kallay MC: Sensitivity, specificity, and predictive values of closed pleural biopsy. Arch Intern Med 144: 325-328, 1984.

4. Prakash UB and Reiman HM: Comparison of needle biopsy with cytologic analysis for the evaluation of pleural effusion: analysis of 414 cases. Mayo Clin Proc 60: 158-164, 1985.

5. Sahn SA: State of the art. The pleura. Am Rev Respir Dis 138: 184-234, 1988.

6. Schönfeld N and Loddenkemper R: Pleural biopsy and thoracoscopy. Eur Respi Mon 9: 135-152, 1998.

7. Von Hoff DD and LiVolsi V: Diagnostic reliability of needle biopsy of the parietal pleura. A review of 272 biopsies. Am J Clin Pathol 64: 200-203, 1975.

8. Dedrick CG, McLoud TC, Shepard JA and Shipley RT: Computed tomography of localized pleural mesothelioma. AJR Am J Roentgenol 144: 275-280, 1985.

9. Leung AN, Muller NL and Miller RR: CT in differential diagnosis of diffuse pleural disease. AJR Am J Roentgenol 154: 487-492, 1990

10. Sahn SA: Malignant pleural effusions. Clin Chest Med 6: $113-125,1985$.

11. Antony VB, Godbey SW, Kunkel SL, Hott JW, Hartman DL, Burdick MD and Strieter RM: Recruitment of inflammatory cells to the pleural space. chemotactic cytokines, IL-8 and monocyte chemotactic peptide-1 in human pleural fluids. J Immunol 151 7216-7223, 1993

12. Ferrara N and Henzel WJ: Pituitary follicular cells secrete a novel heparin-binding growth factor specific for vascular endothelial cells. Biochem Biophys Res Commun 161: 851-858, 1989.

13. Senger DR, Galli SJ, Dvorak AM, Perruzzi CA, Harvey VS and Dvorak HF: Tumor cells secrete a vascular permeability factor that promotes accumulation of ascites fluid. Science 219: 983-985, 1983.

14. Duysinx BC, Corhay JL, Hubin L, Nguyen D, Henket M and Louis R: Diagnostic value of interleukine-6, transforming growth factor-beta 1 and vascular endothelial growth factor in malignant pleural effusions. Respir Med 102: 1708-1714, 2008.

15. Thickett DR, Armstrong L and Millar AB: Vascular endothelial growth factor (VEGF) in inflammatory and malignant pleural effusions. Thorax 54: 707-710, 1999.

16. Allen SJ and Dawbarn D: Clinical relevance of the neurotrophins and their receptors. Clin Sci 110: 175-191, 2006.

17. Bibel M and Barde YA: Neurotrophins: key regulators of cell fate and cell shape in the vertebrate nervous system. Genes Dev 14 2919-2937, 2000.

18. Otten U, Ehrhard P and Peck R: Nerve growth factor induces growth and differentiation of human B lymphocytes. Proc Natl Acad Sci USA 86: 10059-10063, 1989.

19. Nassenstein C, Braun A, Nockher WA and Renz H: Neurotrophin effects on eosinophils in allergic inflammation. Curr Allergy Asthma Rep 5: 204-211, 2005.

20. Wagner N, Wagner KD, Theres H, Englert C, Schedl A and Scholz H: Coronary vessel development requires activation of the TrkB neurotrophin receptor by the Wilms' tumor transcription factor Wt1. Genes Dev 19: 2631-2642, 2005.

21. Paredes A, Romero C, Dissen GA, et al: TrkB receptors are required for follicular growth and oocyte survival in the mammalian ovary. Dev Biol 267: 430-449, 2004.

22. Vega JA, Garcia-Suarez O and Germana A: Vertebrate thymus and the neurotrophin system. Int Rev Cytol 237: 155-204, 2004.
23. Dagnell C, Grunewald J, Idali F, et al: Increased levels of nerve growth factor in the airways of patients with sarcoidosis. J Intern Med 264: 463-471, 2008

24. Fox AJ, Patel HJ, Barnes PJ and Belvisi MG: Release of nerve growth factor by human pulmonary epithelial cells: role in airway inflammatory diseases. Eur J Pharmacol 424: 159-162, 2001.

25. Freund-Michel V and Frossard N: Overexpression of functional TrkA receptors after internalisation in human airway smooth muscle cells. Biochim Biophys Acta 1783: 1964-1971, 2008.

26. Ricci A, Graziano P, Bronzetti E, et al: Increased pulmonary neurotrophin protein expression in idiopathic interstitial pneumonias. Sarcoidosis Vasc Diffuse Lung Dis 24: 13-23, 2007.

27. Garcia-Suarez O, Perez-Pinera P, Laura R, et al: TrkB is necessary for the normal development of the lung. Respir Physiol Neurobiol 167: 281-291, 2009.

28. Prakash Y, Thompson MA, Meuchel L, Pabelick CM, Mantilla CB, Zaidi S and Martin RJ: Neurotrophins in lung health and disease. Expert Rev Respir Med 4: 395-411, 2010.

29. Fanburg-Smith JC and Miettinen M: Low-affinity nerve growth factor receptor (P75) in dermatofibrosarcoma protuberans and other nonneural tumors: a study of 1,150 tumors and fetal and adult normal tissues. Hum Pathol 32: 976-983, 2001.

30. Kruttgen A, Schneider I and Weis J: The dark side of the NGF family: neurotrophins in neoplasias. Brain Pathol 16: 304-310, 2006.

31. Pearse RN, Swendeman SL, Li Y, Rafii D and Hempstead BL: A neurotrophin axis in myeloma: TrkB and BDNF promote tumor-cell survival. Blood 105: 4429-4436, 2005.

32. Knezevich SR, McFadden DE, Tao W, Lim JF and Sorensen PH A novel ETV6-NTRK3 gene fusion in congenital fibrosarcoma. Nat Genet 18: 184-187, 1998.

33. Yang ZF, Ho DW, Lam CT, et al: Identification of brain-derived neurotrophic factor as a novel functional protein in hepatocellular carcinoma. Cancer Res 65: 219-225, 2005.

34. Okada Y, Eibl G, Guha S, Duffy JP, Reber HA and Hines OJ: Nerve growth factor stimulates MMP-2 expression and activity and increases invasion by human pancreatic cancer cells. Clin Exp Metastasis 21: 285-292, 2004.

35. Hoyle GW: Neurotrophins and lung disease. Cytokine Growth Factor Rev 14: 551-558, 2003

36. Ricci A, Greco S, Mariotta S, et al: Neurotrophins and neurotrophin receptors in human lung cancer. Am J Respir Cell Mol Biol 25: 439-446, 2001.

37. Perez-Pinera P, Hernandez T, Garcia-Suarez O, et al: The Trk tyrosine kinase inhibitor K252a regulates growth of lung adenocarcinomas. Mol Cell Biochem 295: 19-26, 2007.

38. Ricci A, Mariotta S, Pompili E, et al: Neurotrophin system activation in pleural effusions. Growth Factors 28: 221-231, 2010.

39. Davidson B, Reich R, Lazarovici P, et al: Expression of the nerve growth factor receptors TrkA and P75 in malignant mesothelioma. Lung Cancer 44: 159-165, 2004.

40. Yilmaz U, Polat G, Sahin N, Soy O and Gulay U: CT in differential diagnosis of benign and malignant pleural disease. Monaldi Arch Chest Dis 63: 17-22, 2005.

41. Davidson B, Reich R, Lazarovici P, et al: Expression and activation of the nerve growth factor receptor TrkA in serous ovarian carcinoma. Clin Cancer Res 9: 2248-2259, 2003.

42. Janis LS and Stein DG: Intraseptal injections of NGF attenuates edema formation following septal lesions in the rat. Neurosci Lett 214: 21-24, 1996.

43. Douma S, van Laar T, Zevenhoven J, Meuwissen R, van Garderen E and Peeper DS: Suppression of anoikis and induction of metastasis by the neurotrophic receptor TrkB. Nature 430: 1034-1039, 2004.

44. Duysinx B, Nguyen D, Louis R, Cataldo D, Belhocine T, Bartsch P and Bury T: Evaluation of pleural disease with 18-fluorodeoxyglucose positron emission tomography imaging. Chest 125: 489-493, 2004.

45. Gupta NC, Rogers JS, Graeber GM, et al: Clinical role of F-18 fluorodeoxyglucose positron emission tomography imaging in patients with lung cancer and suspected malignant pleural effusion. Chest 122: 1918-1924, 2002.

46. Zhu ZW, Friess H, Wang L, Di Mola FF, Zimmermann A and Buchler MW: Down-regulation of nerve growth factor in poorly differentiated and advanced human esophageal cancer. Anticancer Res 20: 125-132, 2000. 